\title{
FATIGUE PROPERTIES OF STEEL WITH INCREASED ATMOSPHERIC CORROSION RESISTANCE
}

The paper deals with the influence of cyclic loading (tension-compression, bending and torsion) on the course of the fatigue life and the fatigue limit of advanced low-alloyed strip steel with increased atmospheric corrosion resistance. The tested steel shows, besides very good mechanical properties $\left(R_{e}>380 \mathrm{MPa}, A_{5}>30 \%\right)$, also very good fatigue resistance and its fatigue limit/ultimate tensile strength ratio is above 0.5. These properties are provided by a favourable fine-grained structure of the tested steel.

\section{Introduction}

Low-carbon low-alloyed Cu-Cr-Ni-P steels serve as qualitatively higher substitution for classic structural materials able to form, under suitable atmospheric conditions, a coherent and very adhesive, aesthetic layer of corrosion products on its surface, which retards the corrosion process $[1,2]$. For the effective utilization of these steels, the endeavour is to increase their utility properties by optimizing their chemical composition, as well as the strip production technology [3].

For the application of these steels, their resistance to cyclic loading - fatigue - is one of substantial requirements. The fatigue process is influenced by internal, as well as external factors. The internal factors are the function of the internal material structure. The external factors are related to the operational conditions of equipment. The environment has a significant influence, since corrosion accelerates the fatigue process even in case of steels with increased atmospheric corrosion resistance, although to a less extent than in case of classic steels [4].

The type of cyclic loading also significantly influences the fatigue process. Literature presents relationships between the fatigue limits of three basic types of cyclic loading (tension-compression, bending, torsion), which can generally be defined using the following equation

$$
\sigma_{C o}=a \cdot \sigma_{C}=b \cdot \tau_{C}
$$

where $\sigma_{C o}, \sigma_{C}, \tau_{C}$ are bending, tension-compression and torsion fatigue limits. The $a, b$ parameters are, besides the loading type, dependent on the internal material structure, but also on the test conditions. It generally applies that $\sigma_{C o}>\sigma_{C}>\tau_{C}$. For steels, $a=1.3$ and $b=1.75$ [5]. The stress distribution on the sample cross-section is different for different cyclic loading types and therefore the material non-homogenity (different structures on the surface and inside the part, residual stress, notch effects of the surface, etc.) influences the relationships between $\sigma_{C o}, \sigma_{C}, \tau_{C}[6]$.

The paper is focused on the assessment of the influence of the cyclic loading type on the fatigue life of sheets made of low-carbon low-alloyed steel with increased atmospheric corrosion resistance with higher utility properties. These sheets are used, among others, for products that are loaded in various ways during operation (e.g. ship transport containers).

\section{Test material and methods}

The fatigue tests were carried out on sheets made of low-carbon $(\mathrm{C}=0.08 \%)$, low-alloyed $(\mathrm{Al}=0.04 \%, \mathrm{Cu}=0.4 \%, \mathrm{Cr}=0.5 \%$ a $\mathrm{Ni}=0.15 \%)$ steel with increased atmospheric corrosion resistance. The methods of determination of the chemical composi-

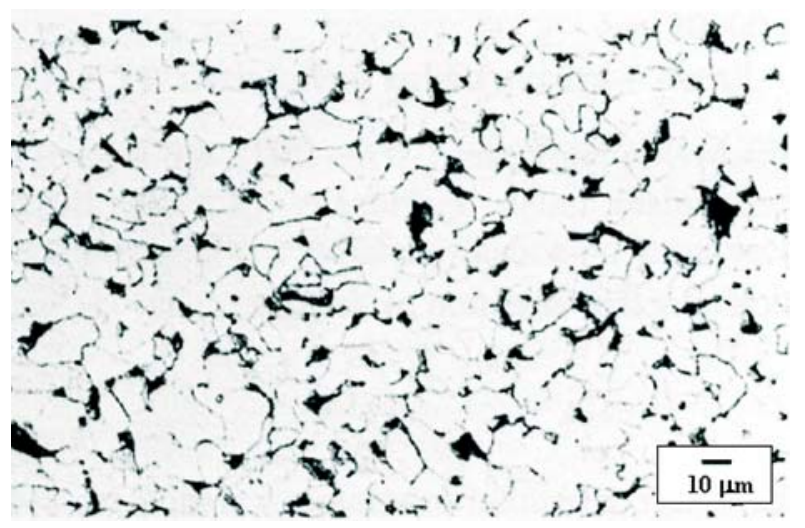

Fig. 1 Microstructure of tested steel

\footnotetext{
* Marian Bursak ${ }^{1}$, Otakar Bokuvka ${ }^{2}$

${ }^{1}$ Department of Material Science, Technical University of Kosice, Slovakia, E-mail: Marian.Bursak@tuke.sk

${ }^{2}$ Department of Materials Engineering, University of Zilina, Slovakia
} 
tion are described in [9]. As a result of controlled hot rolling, the structure observed using light microscopy is fine-grained, polygonal, ferrite-pearlite, with the occurrence of cementite mainly at the grain boundaries, Fig. 1 .

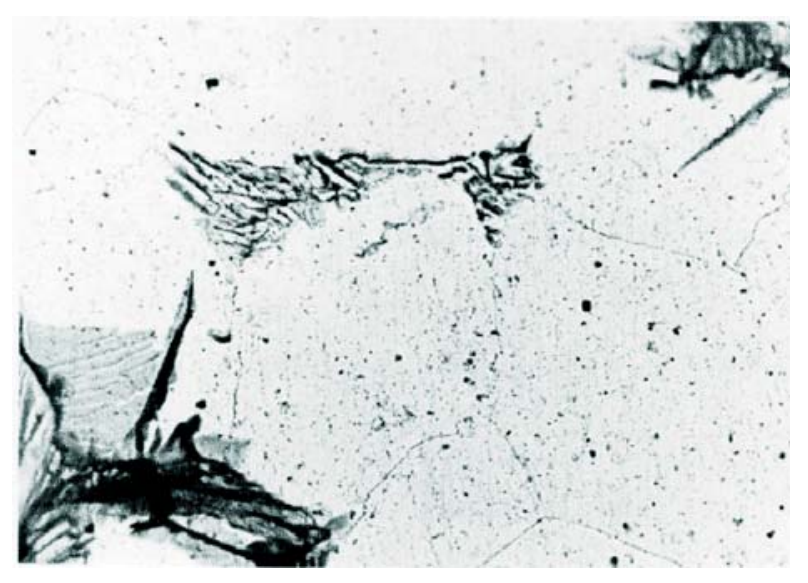

Fig. 2 Distribution of dispersed precipitate. Magnitude: $3000 x$

The mean ferrite grain size is approx. $10.5 \mu \mathrm{m}$ and the pearlite share in the structure is approx. $10 \%$. The precipitate is distributed relatively uniformly in the ferrite matrix, Fig. 2. This structure of the tested steel makes it possible to achieve very good mechanical, as well as fatigue properties. The basic mechanical properties of the tested sheets were determined using the tensile test and are listed in Tab. 1.

Basic mechanical properties of the tested steel

Table 1.

\begin{tabular}{|c|c|c|c|c|}
\hline $\begin{array}{c}\text { Sampling } \\
\text { direction }\end{array}$ & $\begin{array}{c}R_{e} \\
{[\mathrm{MPa}]}\end{array}$ & $\begin{array}{c}R_{m} \\
{[\mathrm{MPa}]}\end{array}$ & $\begin{array}{c}A_{5} \\
{[\%]}\end{array}$ & $\begin{array}{c}Z \\
{[\%]}\end{array}$ \\
\hline $\mathrm{L}$ & 384 & 501 & 31.8 & 71.5 \\
\hline $\mathrm{T}$ & 390 & 498 & 28.7 & 63.3 \\
\hline
\end{tabular}

As it results from Tab. 1, only deformation properties $\left(A_{5}, Z\right)$ are reasonably influenced by the rolling direction - they are higher in the rolling direction $(\mathrm{L})$.

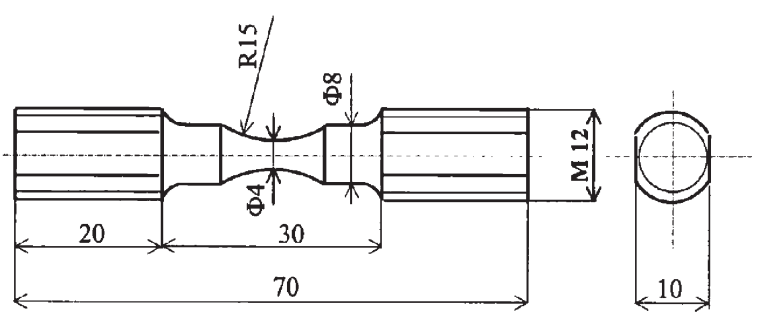

Fig. 3a Fatigue test bar for symmetric alternate tension-compression cyclic loading tests
Samples were taken from the tested strips in the rolling direction $(L)$ and the transversal direction $(T)$ and fatigue test bars were made for symmetric alternate tension-compression cycle tests (Fig. 3a), symmetric alternate torsion cycle tests (Fig. 3b) and symmetric in-plane bending tests (Fig. 4).

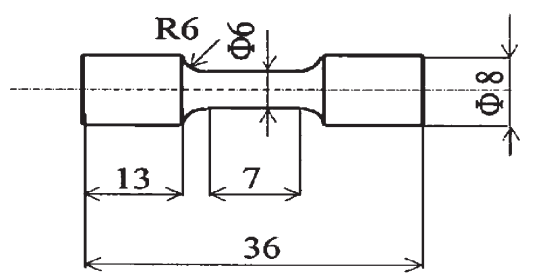

Fig. 3b Fatigue test bar for symmetric alternate torsion cyclic loading tests

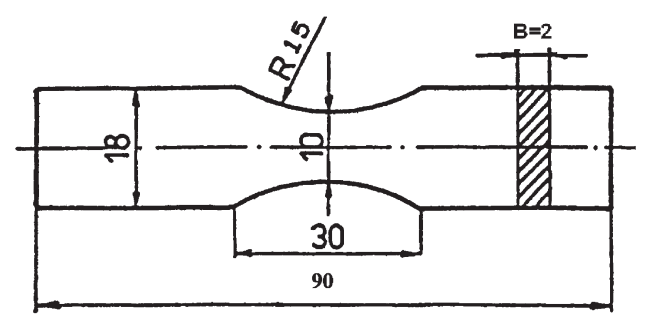

Fig. 4 Fatigue test bar for in-plane bending loading tests

The tension-compression fatigue tests were performed using a standardized performed procedure on the INSTRON 8511 pulsator at the frequency of approx. $27 \mathrm{~Hz}$ with the symmetric alternate cycle $(R=-1)$, and the torsion and in-plane bending tests were executed on the PWOG fatigue machine with the symmetric alternate torsion and bending cycles $(R=-1)$ at the frequency of $35 \mathrm{~Hz}$. The limit number of cycles was $N_{C}=10^{7}$ cycles, in accordance with the standard.

\section{Test results and analysis}

The fatigue test results were processed as the relationship between the upper stress $\sigma$ and the number of cycles to failure $N$. For illustration, Fig. 5 shows the Wöhler curve of the tested steel for the $L$ direction with the symmetric alternate tension-compression cycle and Fig. 6 shows this for the alternate torsion cycle.

The fatigue limits were determined from the horizontal line of the experimentally determined Wöhler curves and the results from the inclined line were statistically processed in the form of a regression relationship, $\log N=a+b . \sigma_{h}$, or $\log N=a+b . \tau_{h}$. The time fatigue limit with $50 \%$ probability of survival for the required number of cycles $N_{p}<2.10^{6}$ can be calculated from these equations. Tab. 2 documents the measured fatigue characteristics of the tested steel. 


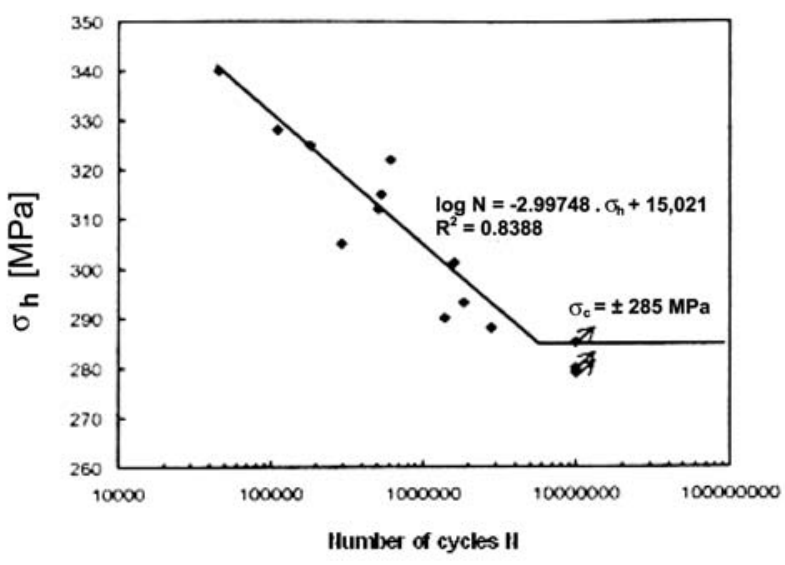

Fig. 5 Wöhler curve for symmetric tension-compression loading in the $L$ direction

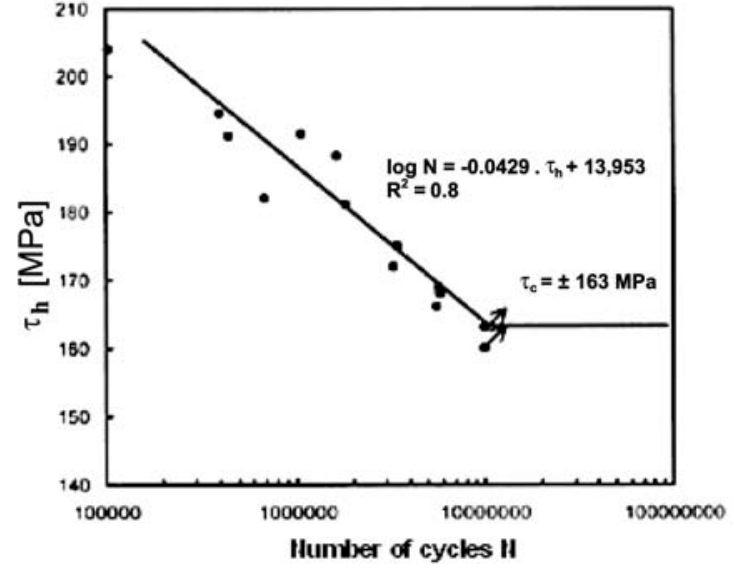

Fig. 6 Wöhler curve for alternate torsion loading in the $L$ direction

Fatigue characteristics of the tested steel

Table 2.

\begin{tabular}{|c|c|c|c|c|c|c|c|c|}
\hline $\begin{array}{c}\text { Loading } \\
\text { method }\end{array}$ & $\begin{array}{c}\text { Sampling } \\
\text { direction }\end{array}$ & $a$ & $b$ & $\begin{array}{c}\sigma_{C} \\
{[\mathrm{MPa}]}\end{array}$ & $\begin{array}{c}\tau_{C} \\
{[\mathrm{MPa}]}\end{array}$ & $\begin{array}{c}\sigma_{C o} \\
{[\mathrm{MPa}]}\end{array}$ & $\begin{array}{c}\sigma_{C}\left(\sigma_{C o}\right) / R_{\mathrm{e}} \\
\tau_{C} / R_{e}\end{array}$ & $\begin{array}{c}\sigma_{C}\left(\sigma_{C o}\right) / R_{\mathrm{m}} \\
\tau_{C} / R_{m}\end{array}$ \\
\hline $\begin{array}{c}\text { Tension- } \\
\text { compression } \\
(R=-1)\end{array}$ & $\mathrm{L}$ & -2.9975 & 15.021 & \pm 285 & - & - & 0.7441 & 0.569 \\
\hline $\begin{array}{c}\text { Torsion } \\
(R=-1)\end{array}$ & $\mathrm{T}$ & -0.0222 & 12.218 & \pm 275 & & & 0.7270 & 0.560 \\
\hline $\begin{array}{c}\text { In-plane } \\
\text { bending }\end{array}$ & $\mathrm{T}$ & -0.0429 & 13.953 & - & \pm 163 & - & 0.4256 & 0.325 \\
$(R=-1)$ & & - & - & - & - & 261 & 0.7560 & 0.513 \\
\hline
\end{tabular}

Tab. 2 shows that the $\sigma_{C} / R_{m}$ ratio is more than 0.5 , which indicates the above-standard utilization of the strength properties of the tested steel during fatigue tension loading. The favourable fatigue properties are the result of the structure of the tested steel, especially its fine grain, which, besides increasing the strength properties, significantly increased its elongation. The high $\sigma_{C} / R_{e}$ ratio (0.72) also indicates good resistance of the tested steel in the low-cycle fatigue area.

The tested sheet was rolled in a unidirectional, controlled way, which was mainly reflected in the anisotropy of plastic properties. In the transversal direction, the elongation $\mathrm{A}_{5}$ and the reduction of area $Z$ were $10 \%$ lower than in the rolling direction. Since the fatigue failure resistance is an integral strength and plasticity property, the anisotropy of properties is also reflected on the fatigue limit value. The tension fatigue limit with the symmetric cycle in the $T$ direction is approx. 3.5\% lower than in the $L$ direction. This anisotropy of plastic properties also influences the behaviour of material when the loading type is changed. The measured results brought the following relationship between the fatigue limits at the symmetric tension-compression, in-plane bending and torsion cycles:

$$
\sigma_{C}=1.05 . \sigma_{C o}=1.69 \cdot \tau_{C} .
$$

The $\sigma_{C} / \sigma_{C o}$ ratio is influenced, among others, by various thicknesses of the input material, but also by the test bar shape (Fig. 4). The flat test bar edges are often the initiators of fatigue crack formation. On flat test bars, the fatigue properties are also significantly influenced by residual stress [4, 7]. Theoretically, the stress size and course at the symmetric tension-compression cycle and at the surface layers of the test bar at the symmetric in-plane bending can be considered as identical. Then the $\sigma_{C} / \sigma_{C o}$ ratio will be dependent on whether the shape and the surface of the flat test bar or the lower tension stress under the surface during in-plane bending has a more significant effect.

The $\sigma_{C} / \tau_{C}$ ratio, because of different stress courses during tension and torsion, is influenced more significantly by the anisotropy of properties of unidirectionally rolled sheets. The effect of the loading method on the fatigue limit values is, among others, based on the strength properties of material and the $\sigma_{C} / \tau_{C}\left(\sigma_{C o}\right)$ ratio cannot be considered as a constant [8]. If we compare the fatigue limit values at the symmetric cycle in in-plane bending and torsion, which were tested on the same equipment, then $\sigma_{C o} / \tau_{C}=$ $=1.6$. This ratio is in accordance with the mean ratios applicable to structural steels.

The tested strip steel with increased atmospheric corrosion resistance has, when compared with classic ferrite-pearlite COR- 
TEN steels, higher strength and plastic properties, which were achieved through suitable production technology. The increased strength properties are the result of contributions from grain refinement and precipitation hardening, while fine grains eliminated the adverse effect of precipitation hardening on plasticity. These properties also provided an above-standard fatigue limit/ultimate tensile strength ratio, even when the cyclic loading type is changed. The tested steel has favourable fatigue properties even after longterm exposure to atmospheric corrosion [4].

\section{Conclusion}

The paper analyses the fatigue properties of fine-grained strip steel with increased atmospheric corrosion resistance at three basic loading types - tension, torsion and bending. Based on the experiments and their analysis, the following can be stated:

- The favourable mechanical properties $\left(R_{e}, R_{m}, A_{5}, Z\right)$ of the tested steel, achieved mainly through grain refinement and precipitation hardening, are also reflected on their above-standard $\sigma_{C} / R_{m}$ ratio.

- The favourable fatigue limit/ultimate tensile strength ratio is maintained also when the cyclic loading type is changed.

- The ratio between the fatigue limits at the above-mentioned cyclic loading types does not significantly differ from the values stated for structural steels. The results show that this ratio is also influenced (besides the material characteristics) by the shape of the used test bars.

\section{References}

[1] SEVCIKOVA, J. TITKOVA, K., SEVCIK, A.: Corrosion and Prevention of Material, vol. 44, 4/2000, p. 82

[2] KOCICH, J., SEVCIKOVA, J.: Basic Problems of Steel Type COR-TEN Application, Metal, vol. 99, Ostrava, 1999, p. 110

[3] KOLLAR, J., SIMON, A.: Steel Sheets, vol. 23, 1/1996, p. 19

[4] BURSAK, M., MICHEL, J.: Communications - Scientific Letters of the University Zilina, 4/2006, p. 38

[5] VECHET, S., KOHOUT, J., BOKUVKA, O.: Fatigue Properties of Nodular Cast Iron (in Czech), Edicne stredisko Zilina, University of Zilina, 2002

[6] BURSAK, M., BOKUVKA, O.: Communications - Scientific Letters of the University of Zilina, 4/2006, p. 34

[7] MIHALIKOVA, M., KOVALOVA, K., MICHEL, J.: Materials Engineering, vol. 11, 3/2004, p. 13

[8] TOUSCHER, H.: Dauerfestigkeit von Stahle und Gusseisen, VEB Fachbuchverlag Leipzig, 1982

[9] RUZICKOVA, S.: An Indian Journal, vol. 6, 1/2007, pp. 17-26. 